\title{
EL CASTIGO EN EL DERECHO ADMINISTRATIVO
}

\author{
CRISTIAN ROMÁN CORDERO* \\ Universidad de Chile
}

\begin{abstract}
RESUMEN: El autor expone la importancia actual de la atribución de potestades sancionadoras a la Administración del Estado. Plantea que tal atribución no importa infracción constitucional alguna, pero advierte que su ejercicio debe estar circunscrito a principios, tanto de orden sustantivo como adjetivo. Para la construcción dogmática de tales principios parte afirmando la autonomía del Derecho Administrativo Sancionador respecto del Derecho Penal. No obstante ello, sostiene que, por razones de urgencia, los principios sustantivos del primero deben construirse dogmáticamente a partir de los principios del segundo, los cuales deben ser considerados para este efecto como pauta y cota máxima, debiendo, en consecuencia, ser aplicados al Derecho Administrativo Sancionador "por regla general", reconociendo, por tanto, excepciones y matizaciones. Tales principios serían, a su juicio, los de legalidad, tipicidad, proporcionalidad, ne bis in idem, etcétera. En cuanto a los principios adjetivos o procedimentales, advierte que la imposición de toda sanción administrativa debe necesariamente ser la conclusión de un procedimiento justo y racional. Finalmente, destaca la importancia de precisar el concepto de "sanción administrativa", la cual al ser un concepto jurídico indeterminado, como muchos otros en el Derecho Público, debe ser precisado, caso a caso, por la jurisprudencia. No obstante ello, expone algunas características básicas de la sanción administrativa.
\end{abstract}

Palabras clave: Derecho Administrativo, Derecho Administrativo Sancionador, potestad sancionadora, sanciones administrativas.

ABSTRACT: The author exposes the current importance of the attribution of punitive powers to the State Administration. He proposes that such attribution implies no constitutional infringement, though he warns that its exercise should be restricted to principles, both substantive and adjective. For the dogmatic construction of such principles he begins affirming the autonomy of the Administrative Punitive Law on the Criminal Law. Nevertheless, he argues that, for reasons of urgency, the substantive principles of the first should be built dogmatically from the principles of the second, which should be considered for this purpose as guide and peak, and must, therefore, be applied to the Administrative Punitive Law as a "general rule", recognizing, in consequence, exceptions and refinements. Such principles would be, from his view, legality, criminality, proportionality, ne bis in idem, etc. In regard to the adjective or procedural principles, he warns that the imposition of any administrative sanction must necessarily be the conclusion of a due process. Finally, he underscores the importance of defining the concept of "administrative sanction", wich, being an indeterminate legal concept, as many others in the Public Law, must be clarified, case by case, by the jurisprudence. However, he exposes certain basic features of the administrative sanction.

Key words: Administrative Law, Administrative Punitive Law, powers of sanction, administrative sanction.

"Es algo que parece inesplicable, por ejemplo, cómo el artículo 106 de la lei del réjimen
interior pudo conferir jurisdicción a los Gobernadores para imponer multas que no
excedieran de veinticinco pesos, o, en su defecto, prisión que no excediera de cuarenta $i$
ocho horas, a los individuos que les desobedecieran o faltaran al respecto, i a los que
turbaran el órden o sosiego público; i como el articulo 120 de la misma lei pudo conferir

\footnotetext{
* Abogado, Licenciado en Ciencias Jurídicas y Sociales (Universidad de Chile), Magíster en Derecho Público (Universidad
} de Chile), Instructor de Derecho Administrativo de la Universidad de Chile (croman@derecho.uchile.cl) 
facultad a aquellos funcionarios para imponer hasta un mes de prision o hasta veinticinco palos, a los soldaddos de policía i a otros ajentes de la misma clase, que incurrieran en faltas u omisiones que no tuvieran pena determinada en el Código criminal. Hoi, por fortuna, nuestro Código Penal tiene previstos los casos a que esas dos disposiciones se refieren, $i$ ha derogado, por consiguiente, o dejado sin efecto la anómala jurisdicción que ámbas atribuian a los Gobernadores departamentales, evitando asi que estos puedan ser jueces en causa propia i que puedan aplicar paternalmente la pena de palos a los infelices subalternos de la policía.!El rubor asoma a las mejillas cuando se piensa que semejante réjimen, abiertamente contrario a la Constitución i a los sanos principios, ha sido, sin embargo, el réjimen legal de nuestra República durante largos años!".

Huneeus, Jorge. La Constitución ante el Congreso. $1^{\mathrm{a}}$ edición. Santiago, Imprenta de "Los Tiempos", 1880, tomo II, p. 244.

\section{INTRODUCCIÓN}

Respondiendo a la convocatoria del presente número de la Revista de Derecho y Humanidades, relativa al "castigo", envío el presente artículo, que estudia y analiza la forma en la que aquel se manifiesta en el Derecho Administrativo, esto es, la sanción administrativa y, a su vez, los límites constitucionalmente exigidos para el legítimo ejercicio por parte de la Administración de sus potestades sancionadoras.

Para este cometido, en primer lugar, trataré los fundamentos que justifican la atribución de tales potestades a la Administración y la necesidad de su limitación; luego, me referiré a la autonomía del Derecho Administrativo Sancionador y a los principios que lo informan; y finalmente, abordaré el concepto de "sanción administrativa".

\section{LAS POTESTADES SANCIONADORAS DE LA ADMINISTRACIÓN DEL ESTADO}

\section{FUNDAMENTOS DE LA ATRIBUCIÓN LEGAL DE POTESTADES SANCIONADORAS A LA ADMINISTRACIÓN}

Desde el momento mismo en el que es posible hablar de Administración en los términos que hoy la entendemos ${ }^{1}$, aquella tiene atribuidas potestades sancionadoras. Así, por ejemplo, el libro Principios Elementales de Derecho Administrativo Chileno, primero en Chile y Latinoamérica sobre la especialidad ${ }^{2}$, de 1859, atribuido a don Santiago Prado, ya se refiere a ellas. Sobre el particular puntualiza que su atribución a la Administración debía ser, en primer lugar, excepcional, razón por la cual, entiende, aquello debía estar reservado a la ley, y en segundo lugar, limitada, esto es, las sanciones que la Administración podía, en su ejercicio, imponer en caso alguno debían exceder la "simple corrección o

\footnotetext{
${ }^{1}$ Sobre el particular véase: GiAnInNi, Massimo Severo. Premisas Sociológicas e Históricas del Derecho Administrativo. -1a ed.- Madrid: Instituto Nacional de Administración Pública, 1980.

${ }^{2}$ Cfr. Villegas Basavilbaso, Benjamín. Derecho Administrativo. - $1^{\mathrm{a}}$ ed.- Buenos Aires: Tipográfica Editora Argentina, 1949, Tomo I, p. 49.
} 
por vía de disciplina" ${ }^{3}$. Criterios que siguieron, por una parte, el Código Penal de 1875, al establecer que la Administración podía imponer sanciones, mas ellas no debían exceder las señaladas en su Libro III, salvo que una ley expresamente dispusiera lo contrario ${ }^{4}$, y por otra, la doctrina, uniformemente, durante buena parte del siglo $\mathrm{XX}^{5}$.

Ahora bien, hace poco más de medio siglo, especialmente en las últimas décadas, se aprecia un crecimiento exponencial de la cantidad de órganos administrativos que han sido dotados con tales potestades por ley expresa ${ }^{6}$, así como de la lesividad de las sanciones que estos pueden imponer en su ejercicio; fenómeno que, por enorme e inorgánico, he denominado elefantiasis de las potestades sancionadoras de la Administración 7 .

Este fenómeno ha sido cuestionado por un importante sector doctrinario. Para ello se ha afirmado que aquel constituye una irrupción desmedida de la Administración en el libre juego de las leyes del mercado ${ }^{8}$ y, además, que la atribución de tales potestades a la Administración contravendría la Constitución, ya que, sostienen Aróstica Maldonado ${ }^{9}$ y

\footnotetext{
3 La posición del mencionado autor puede apreciarse en el siguiente párrafo extraído de su Principios Elementales de Derecho Administrativo: "La independencia de la administracion estaría comprometida sino tuviese ninguna potestad coercitiva o careciese absolutamente de facultades para exijir la fiel observancia de sus actos, aplicando penas pecuniarias dentro de los límites de la simple corrección o por vía de disciplina. El poder legislativo delega en la administracion esta parte de funciones propias del órden judicial, a fin de robustecer su acción i completar su existencia, reservando el conocimiento de las causas graves i de los delitos contra la autoridad a los jueces competentes" (sic) PRADO, Santiago. Principios Elementales de Derecho Administrativo Chileno. - $1^{\text {a }}$ ed.- Santiago: Imprenta Nacional, 1859, p. 24.

${ }^{4}$ En efecto, el artículo 501 del Código Penal dispuso: "En las ordenanzas municipales y en los reglamentos generales o particulares que dictare en lo sucesivo la autoridad administrativa no se establecerán mayores penas que las señaladas en este Libro, aun cuando hayan de imponerse en virtud de atribuciones gubernativas, a no ser que se determine otra cosa por leyes especiales".

${ }^{5}$ Así, por ejemplo, un libro intitulado Derecho Administrativo, sin autor, de 1929, señala en este sentido que: "La potestad correctiva, como se ha dicho, se aplica a los administrados cuando infringe alguna disposición administrativa. Esta potestad se contiene en la ley, pero más generalmente en los reglamentos orgánicos y se le da a la autoridad correspondiente y al jefe del servicio. Las correcciones no tienen el carácter de pena. En primer lugar por su naturaleza misma y en segundo, porque, como dijimos en otra ocasión, así lo establece el art. 20 del Código Penal. De eso se deduce que las correcciones no producen el efecto que llevan aparejadas las penas, como inhabilidad, etc. Las correcciones tiene un segundo carácter distintivo y es el no poder constituir un castigo mayor que el del Código citado impone a las faltas, salvo que la ley administrativa disponga otra cosa. Esto lo prescribe el art. 501 del Código Penal”. Autor desconocido. Derecho Administrativo. Santiago, 1929, p. 48. En todo caso no es posible dejar de observar la lamentable omisión que sobre el tema se advierte en las obras holísticas de la especialidad en el periodo referido.

${ }^{6}$ Cfr. Fuentes Hurtado, Martín. Derecho Administrativo Penal. -1 a ed.- Santiago: Editorial Universitaria, 1954. Por ello, Aróstica Maldonado sostiene que, "a poco andar el siglo XX, la referencia cuasi marginal que el artículo 501 hacía a las "leyes especiales" abre las puertas, de par en par, a los poderes sancionatorios administrativos, por medio de un cúmulo enorme e incoherente de preceptos legales en tal sentido". ARóstica Maldonado, Iván, "Un Lustro de Sanciones Administrativas (1988-1992)", en Revista de Derecho Público, Departamento de Derecho Público, Facultad de Derecho, Universidad de Chile, No 50, julio-diciembre 1991, p. 77.

7 Román Cordero, Cristian. "Los principios de Derecho Administrativo Sancionador", en Revista de Derecho Público, Departamento de Derecho Público, Facultad de Derecho, Universidad de Chile, No 69/2, 2007, pp. 24 y ss.

${ }^{8}$ Sostiene al respecto Aróstica: "Resulta verdaderamente paradojal comprobar que mientras se viene abogando por el "fin del estatismo”, esto es, por el término o al menos la reducción de omnímodos poderes en manos de la Administración, en aras de concretar el justo equilibrio que entre estos y los derechos de los ciudadanos requiere una sociedad verdaderamente libre, no se ha reparado mientes en la conservación e incluso aumento que han experimentado sus potestades sancionadoras con respecto a esos particulares". ARÓSTICA MALDONADO, Iván, op. cit. (n. 6), p. 71.

${ }^{9}$ Aróstica Maldonado ha planteado: "De esta forma, perfectamente puede concluirse que la potestad sancionadora administrativa es totalmente inconstitucional, ya que la facultad de imponer penas y sanciones por contravenciones a la normativa vigente le corresponde exclusivamente a los únicos órganos jurisdiccionales: los Tribunales de Justicia, por expresa disposición del inciso cuarto del No 3 del artículo 19 y del artículo 73, ambos de la Constitución". AróstiCA MALdONADO, Iván. "Algunos problemas del Derecho Administrativo Penal”, en Revista de Derecho, Universidad de Concepción, No 182, 1987, p. 74.
} 
Soto Kloss ${ }^{10}$, coincidiendo con lo señalado hace más de un siglo por don Jorge Huneeus ${ }^{11}$, sancionar es juzgar y quien puede juzgar, a la luz de la Carta Fundamental, solo es el juez, mas no el administrador.

Difiero de la opinión de estos connotados profesores. Ello porque hoy se evidencia la conformación de una nueva sociedad -posmoderna y globalizada-, en la que distintos actores, de una u otra manera, con su acción u omisión, crean relevantes riesgos, en los ámbitos especializados en los que se desenvuelven, que pueden derivar en importantes daños para las personas o cosas -incluso mayores que los que amenaza, con su actuación, la misma Administración-. Lo anterior, que parece ser una verdad indiscutible, exige, por cierto, una reelaboración del concepto de Estado de Derecho y, a su vez, de los fines del Derecho Público, puesto que hoy, para atender a este nuevo orden de cosas, no puede seguir siendo el fin y objeto de aquellos conformar a los imperativos de esa rama del Derecho solo a los órganos del Estado, sino que también a los particulares, en especial aquellos que, de hecho o de derecho, en este nuevo escenario, detentan formidables poderes en el seno social ${ }^{12,13}$, sana doctrina que el Tribunal Constitucional ha hecho suya

\footnotetext{
10 Por su parte, Soto Kloss ha planteado que, "si sancionar es juzgar, y si para juzgar se requiere estar habilitado jurídicamente por la Constitución y el ordenamiento constitucional, y ello en Chile se ha entregado a los tribunales de justicia, y más encima ello debe hacerse a través del debido procedimiento (racional y justo), no parece sino elemental el preguntarse ¿̨ómo, entonces, el administrador -sea el Presidente de la República, un jefe de servicio, un intendente, etc.- puede imponer sanciones administrativas sean multas, sean comisos, sean clausuras de locales, sean retiros de actos autorizatorios, sean conductas determinadas, etc. si carece constitucionalmente de jurisdicción? Si el Presidente de la República carece de toda potestad jurisdiccional, y para ordenar detenciones la Constitución ha debido regular expresamente tal posibilidad, y para el caso del estado de sitio ¿cómo es que la Administración que le está subordinada puede imponer sanciones? Porque es una realidad que día a día la Administración impone castigos, no solo a sus agentes (funcionarios), sino a los simples ciudadanos, a los usuarios de servicios públicos, a quienes contratan con ella, a quienes son beneficiarios de una autorización, de una subvención, de un acto de admisión, en fin de cualquier acto administrativo de beneficio" SOTO KLOSS, Eduardo. "Derecho Administrativo Penal. Notas para el estudio de la potestad sancionadora de la Administración”, en Boletín de Investigaciones, Facultad de Derecho, Pontificia Universidad Católica de Chile, No 44 /45, 1979/1980, pp. 95 y ss.

${ }^{11}$ Este autor señaló sobre el particular lo que sigue: "No se concibe, en efecto, cómo un hecho al cual la lei no señala pena pudiera ser delito, i cómo es posible que, señalándosela una lei especial, solo porque esta no tiene el nombre o título de Código Penal, o solo porque no forma parte de este, ese hecho pueda ser castigado por otra autoridad que los Tribunales Ordinarios de Justicia. Según este curioso sistema, el hecho prohibido i castigado por la lei era o no era delito, tomando en cuenta solamente si esa ley formaba o no parte del Código Criminal, según las palabras de nuestra ley de réjimen interior. ¡Es concebible absurdo semejante!” HunEeUS, Jorge. La Constitución ante el Congreso. Tomo II - $1^{\text {a }}$ ed.- Santiago: Imprenta de "Los Tiempos", 1880, pp. 244-245.

12 En este sentido Esteve Pardo ha planteado: "en los últimos tiempos se han formado en el seno de la sociedad, al margen del Estado, unos poderes formidables, como no se habían conocido hasta ahora. Las fuerzas de la economía han abierto circuitos y formado organizaciones de muy difícil control por el Estado al que, por lo demás, llegan a conmocionar con sus movimientos. Por otro lado, el impulso tecnológico, al avanzar de manera tan trepidante y por tan diversos frentes, ha configurado unos espacios que, por su complejidad y su extensión, resultan impenetrable para los poderes públicos. Unas organizaciones al margen de las estructuras estatales tienden a imponer su dominio en esos ámbitos: las telecomunicaciones, la biotecnología, la energía la industria, los medios de comunicación; y, en no pocos casos, ese poder ni tan solo se nuclear o articula en torno a una organización visible, sino que parece brotar súbitamente, desbordado, al extenderse una tecnología, como es el caso de internet, o al estallar un enigma de la ciencia como ocurre ahora con el genoma humano. Así es como estos poderes se constituyen y desenvuelven en muy buena medida al margen de la regulación e intervención de los poderes públicos estatales por la sencilla razón de que les resultan inaccesibles y, por ello, incontrolables”. ESTEVE PARDo, José. Autorregulación. Génesis y efectos. -1ª ed.- Madrid: Editorial Civitas, 2002, pp. 21-22.

${ }^{13}$ En este sentido Esteve Pardo ha expresado: "En cualquier caso, es ya historia la sujeción a normas jurídicas de los poderes públicos lo que, como es notorio, constituye el objetivo y la razón del ser del Estado de Derecho en el que estamos instalados. La paradoja está hoy en el problema que a ese Estado de Derecho se le plantea: no se trata ya del
} 
recientemente ${ }^{14}$. Para tal cometido, como resulta evidente, el Estado tiene el deber jurídico de actuar a efectos de evitar que tales riesgos - derivados de actividades complejas y cuyo control pertenece a particulares- deriven en daños a terceros ${ }^{15}$, deber que concreta, por una parte, normando esos sectores -o incentivando aquello, cuando por la especialidad del sector le resulta imposible, mediante la técnica de la autorregulación ${ }^{16}-$ y, por otro, sancionando la infracción de tal normativa, lo cual, precisamente por la marcada especialización de esos sectores, no podrían satisfactoriamente realizar los tribunales ordinarios de justicia ${ }^{17}$.

sometimiento a Derecho del propio Estado, sino del sometimiento a Derecho de la sociedad o de alguno formidables poderes que en ella se han formado". Esteve PARDO, José, op. cit. (n. 12), p. 24. Asimismo, Cantero Martínez ha señalado: "Por otro parte, hemos de tener en cuenta que el propio surgimiento del Derecho Administrativo se ha explicado tradicionalmente en la necesidad de dotar también a los ciudadanos de ciertas garantías ante el ejercicio de estas potestades (los privilegios en más y en menos de los que hablaba Rivero). Por ello, ante este nuevo fenómeno, no es de extrañar que algunos autores comiencen a plantearse la necesidad de reorientar o redimensionar el tradicional carácter garantista del Derecho Administrativo, que se ha articulado clásicamente en torno al establecimiento de las garantías necesarias frente al ejercicio del poder público en la búsqueda por la satisfacción de los intereses generales. En el momento presente, no obstante, el recurso a la autorregulación pone de manifiesto que ahora es en la propia sociedad, en los sujetos privados y no en los poderes públicos donde empiezan a residenciarse básicamente los más reveladores poderes económicos, tecnológicos, científicos, de comunicación e información, por lo que podríamos plantearnos hasta qué punto no empezaría a ser conveniente establecer esos mismos límites, esas mismas o semejantes garantías para los ciudadanos ante los nuevos sujetos que detentan estos formidables poderes". CANTERO MARTínEZ, Josefa. "La incidencia de la técnica y de las transformaciones sociales en el Derecho Administrativo: el recurso de la denominada "autorregulación regulada", en: Punzón Moraleda, Jesús (Coordinador). Administraciones Públicas y Nuevas Tecnologías. 1a edición, Valladolid, Editorial Lex Nova, 2005, pp. 340-342. En el mismo sentido, véase: NieTo GARCÍA, Alejandro. "Recensión al libro de Esteve Pardo: Autorregulación. Génesis y efectos”, en Revista de Administración Pública, No 160, 2003, p. 429. ROMÁN CORDERO, Cristian. "Neoadministrativismo(s)", en Revista de la Asociación Internacional de Derecho Administrativo, No 4, juliodiciembre 2008, p. 266 y ss.

${ }^{14}$ En este sentido dicha Magistratura recientemente ha afirmado: "Que el deber de los particulares y de las instituciones privadas de respetar y promover el ejercicio de los derechos consustanciales a la dignidad de la persona humana en cuanto a su existencia y exigibilidad, se torna patente respecto de aquellos sujetos a los cuales la Constitución, como manifestación del principio de subsidiariedad, les ha reconocido y asegurado la facultad de participar en el proceso que infunde eficacia a los derechos que ella garantiza. Tal es, exactamente, lo que sucede con las Instituciones de Salud Previsional, en relación con el derecho de sus afiliados a gozar de las acciones destinadas a la protección de la salud, consagrado en el artículo 19, No 9, de la Constitución” (STC 976, C-36).

15 Cfr. Doménech Pascual, Gabriel. Derechos Fundamentales y Riesgos Tecnológicos. El Derecho del ciudadano a ser protegido por los poderes públicos. -1 ${ }^{a}$ ed.- Madrid: Centro de Estudios Políticos y Constitucionales, 2006.

${ }^{16}$ Cfr. Darnaculleta Gardella, María Mercè. Autorregulación y Derecho Público: la autorregulación regulada. - $1^{\mathrm{a}}$ ed.-, Madrid-Barcelona, Marcial Pons, 2006. MuÑoz Machado, Santiago, Tratado de Derecho Administrativo y Derecho Público General, - $1^{\text {a }}$ ed.- Madrid: Civitas, 2004, I, pp. 1248 y ss.

17 En este sentido, Carretero y Carretero han sostenido: "Los confines entre la competencia judicial y administrativa son históricos, y si bien el fondo de la cuestión puede ser penal, cuando median consideraciones de eficacia y de oportunidad, la competencia judicial exclusiva para imponer siempre y en todo caso sanciones resultaría inapropiada. Si, en principio, la determinación de las penas es judicial, en otras ocasiones la potestad jurisdiccional del Estado, en sentido punitivo, se atribuye a la Administración como medio de coacción para obtener el cumplimiento de los deberes de los administrados" Carretero Pérez, Adolfo y Carretero SÁnchez, Adolfo. Derecho Administrativo Sancionador. - $1^{a}$ ed.- Madrid: Edersa, 1992, p. 15. Del mismo modo, Villar Ezcurra ha planteado que: "Históricamente ha sido siempre consustancial al poder público el reconocimiento de la facultad para imponer sanciones como consecuencia de la infracción de las obligaciones o prohibiciones impuestas por el mismo poder. Se trata, simplemente, de una consecuencia lógica ya que si la facultad no existiese no podía garantizarse el cumplimiento de tales obligaciones o prohibiciones. En esencia este es el fundamento de la potestad sancionadora pero con matizaciones muy importantes a partir del constitucionalismo e implantación del Estado de Derecho. En primer lugar que la utilización de la coacción corresponde en esencia a los Tribunales de Justicia, con lo cual la potestad sancionadora de la Administración solo podrá ser concebida como algo residual. En segundo término que, como toda potestad, debe estar reconocida por una norma y sometida en su ejercicio al Derecho". VILLAR EzCURRA, José Luis. 
Finalmente, cabe apuntar, para alejar toda sombra de duda sobre el particular, que coincido absolutamente con lo observado por el Tribunal Constitucional de España en orden a que más inconstitucional que la aparente inconstitucionalidad de la atribución de las potestades sancionadoras de la Administración, sería así declararlo ${ }^{18}$.

\section{FUNDAMENTOS DE LA NECESIDAD DE ESTABLECER LIMITACIONES AL EJERCICIO DE PO- TESTADES SANCIONADORAS POR LA ADMINISTRACIÓN}

Cabe hacer presente que si bien defiendo, como he señalado precedentemente, tanto la constitucionalidad como la conveniencia de la atribución legal de las potestades sancionadoras a la Administración, no puedo dejar de observar, con el mismo énfasis, que necesario es que su ejercicio esté limitado dentro de contornos claros y precisos, y que fijan, primeramente, sus principios, y luego, sus reglas, estadio del que, lamentablemente, hoy lejos nos hallamos ${ }^{19}$. La razón de tal necesidad radica en que, como resulta evidente, tales potestades son potencialmente lesivas de los derechos fundamentales del perseguido (en efecto, la sanción es, en esencia, un mal proferido a un individuo por la infracción del

Derecho Administrativo Especial. -1 a ed.- Madrid: Editorial, Civitas, 1999, p. 87. Igualmente, Ángeles de Palma del Teso ha establecido: "Parece, por tanto, que no podemos dejar de reconocer que la finalidad última del Derecho punitivo -prevenir la lesión o puesta en peligro de los bienes jurídicos que la sociedad ha decidido proteger- se alcanza de forma más efectiva dotando de potestad sancionadora a la Administración. Esta es el instrumento a través del cual el Gobierno ejerce su función ejecutiva. A la Administración interventora, propia de un Estado Social, se le han de reconocer potestades para ordenar y gestionar determinados ámbitos de la vida; y un cumplimiento eficaz de estas funciones pasa por depositar en sus manos una parte del poder punitivo del Estado. Teniendo en cuenta, además, la mayor inmediación de la Administración, en estos casos, con los hechos sancionados". DE PALMa Del Teso, Ángeles. El principio de culpabilidad en el Derecho Administrativo sancionador. $-1^{\text {a }}$ ed.- Madrid: Editorial Tecnos, 1996, p. 37. Igualmente, Nieto ha dicho que "La potestad sancionadora de la Administración es tan antigua que como esta misma y durante varios siglos ha sido considerada como un elemento esencial de la Policía. A partir del constitucionalismo, sin embargo, cambiaron profundamente las concepciones dominantes, puesto que el desprestigio ideológico de la Policía arrastró consigo inevitablemente el de la potestad sancionadora de la Administración, cuya existencia terminó siendo negada en beneficio de los Jueces y Tribunales, a los que se les reconocía el monopolio estatal de la represión. Los tiempos, con todo, han seguido cambiando y hoy casi nadie se atreve ya a negar la existencia de tal potestad -puesto que sería negar la evidencia-, aunque abunden los reproches nostálgicos y se abogue ocasionalmente por el mantenimiento o restablecimiento del monopolio judicial, al que se atribuye -cerrando los ojos a la realidad-el compendio de todas las perfecciones, incluidas las de la justicia, economía y eficacia”. NiETo, Alejandro. Derecho Administrativo Sancionador. $-3^{\text {a }}$ ed.- Madrid: Editorial Tecnos, 2002, p. 22.

${ }^{18}$ En efecto, el Tribunal Constitucional de España ha planteado, en este sentido, que "No cabe duda que en un sistema en que rigiera de manera estricta y sin fisuras la división de poderes del Estado, la potestad sancionadora debería constituir un monopolio judicial y no podría estar nunca en manos de la Administración, pero un sistema semejante no ha funcionado nunca históricamente y es lícito dudar que fuera incluso viable, por razones que no es ahora momento de exponer con detalle, entre las que se pueden citar la conveniencia de no recargar en exceso las actividades de la Administración de Justicia como consecuencia de ilícitos de menor gravedad, la conveniencia de dotar de una mayor eficacia el aparato represivo en relación con ese tipo de ilícitos y la conveniencia de una mayor inmediación de la autoridad sancionadora respecto de los hechos sancionados" (STCE de 3 de octubre de 1983). A su vez, el Tribunal Supremo de dicho país ha afirmado: "La Administración, que resignó en los Tribunales muchas de sus potestades represivas, conservó en sus manos - como señala la doctrina- un evidente poder penal residual, al margen de teorías sobre división o separación de poderes y funciones. Nuestra norma Básica ha constitucionalizado esta potestad" (STS 8 de octubre de 1988).

19 "El problema actual no es el de la existencia de la potestad administrativa sancionadora, y ni siquiera el de su justificación, sino mucho más sencillamente -y también mucho más eficazmente- el de su juridificación. No se trata ya (en otras palabras) de devolver a los jueces potestades indebidamente detentadas por la Administración sino conseguir que esta ofrezca en su ejercicio las mismas garantías que los jueces y procesos penales. Y así, la "despenalización” de los procedimientos y garantías". NiETO, Alejandro. op. cit. (n. 17), p. 84. 
ordenamiento jurídico) y, en este contexto, el establecimiento de principios en los términos referidos no solo consolidaría, en este ámbito, el Estado de Derecho ${ }^{20}$, sino que, además, impediría que, en el ejercicio de tales potestades, se lesionen los derechos y garantías del perseguido $^{21}$ (aunque advirtiendo desde ya que esta rama no es, en lo absoluto, como el Derecho Penal, garantismo puro), evitaría un trato desigual en el ejercicio de tales potestades por distintos organismos administrativos respecto de casos análogos, y desincentivaría la natural tendencia a infringir el ordenamiento jurídico cuando este, al parecer laxo o impreciso, crea la ilusión -y no pocas veces, realidad- de que fácil es eludir la responsabilidad derivada de su contravención.

\section{LA AUTONOMÍA DEL DERECHO ADMINISTRATIVO SANCIONADOR}

Algunos autores plantean que el Derecho Administrativo Sancionador es una rama del Derecho Penal y, por tanto, regida por los principios de este último -al modo penal-, sino por sus reglas ${ }^{22}$. Para afirmar aquello sostienen, en primer lugar, que entre la sanción administrativa y la pena existe una identidad ontológica, existiendo entre ellas tan solo diferencias de grado o intensidad, y, en segundo lugar, que tanto el Derecho Penal como el "Penal Administrativo" -como ellos llaman al Derecho Administrativo Sancionador-son manifestación de un mismo y único ius puniendi del Estado.

Difiero abiertamente de esta posición como de sus argumentos. Para ello advierto, en cuanto al fundamento que apela a la ontología de la sanción ${ }^{23}$, que aquel análisis pertenece a la filosofía y, por tanto, resulta absolutamente ajeno a aquello que nos convoca: determinar con arreglo a qué principios o reglas jurídicas debe sujetarse el ejercicio de las potestades sancionadoras de la Administración y, en efecto, nada obsta para que, por muy idénticos que sean desde la perspectiva ontológica dos fenómenos o institutos, estén regidos por regímenes

\footnotetext{
${ }^{20}$ En este sentido, Sergio Politoff ha señalado que "Los abusos a que tales medidas -sanciones administrativas- pueden conducir a los graves reparos que suscita su utilización, sobre todo cuando ella quebranta los criterios de respeto de la dignidad y de los derechos fundamentales de la persona que deben servir de freno a los excesos del poder político. Sin embargo "si se quiere realmente un auténtico Estado de Derecho democrático", la aplicación de esas facultades -limitada a los casos permitidos por la Constitución- deberá responder de una necesidad ineludible y sujetarse a los criterios de moderación, proporcionalidad y subsidiariedad”. PoliTOff LifSCHITZ, Sergio. Derecho Penal. -2a ed.-, Santiago: Editorial Jurídica ConoSur, 2000, pp. 37-38.

${ }^{21}$ Ya en 1960, Eduardo Novoa Monreal planteaba, describiendo este crecimiento inorgánico de las potestades sancionadoras, que "La proliferación actual de leyes penales administrativas y la mayor gravedad que gradualmente van asumiendo las sanciones que ellas establecen (las leyes sobre Pesca y Caza establecen penas privativas de libertad), hace aconsejable que el legislador se preocupe de rodear a la aplicación del Derecho Penal Administrativo de garantías semejantes a las que están incorporadas al Derecho Penal, como forma adecuada para mantener el respeto por la dignidad y los derechos del hombre" Novoa Monreal, Eduardo, Derecho Penal. Tomo I, Santiago: Editorial Jurídica de Chile, 1960, p. 74.

22 Sobre el particular véase mi crítica a la jurisprudencia administrativa (dictamen No 14.571/2005 de la Contraloría General de la República) en cuanto ha aplicado reglas precisas del Derecho Penal en la resolución de problemas propios del Derecho Administrativo Sancionador: Román Cordero, Cristian. "Derecho Administrativo Sancionador: Ser o no ser. He ahí el dilema”. en: PAntoja BaUZÁ, Rolando (coord.). Derecho Administrativo: 120 años de cátedra. $-1^{\text {a }}$ ed.-, Santiago: Editorial Jurídica de Chile, 2008, pp. 135-136.

23 Para la Real Academia de la Lengua ontología es: "Parte de la metafísica, que trata del ser en general y de sus propiedades trascendentales”. Diccionario de la Real Academia de la Lengua Española. -21a ed.- Madrid: Espasa Calpe, 1992 , p. 1047.
} 
jurídicos distintos ${ }^{24}$. Ahora bien, en cuanto al fundamento relativo a la existencia de un único ius puniendi estatal, de tal ficción -ya que no puede calificársele de otra manera-, posible es concluir precisamente lo contrario, ya que conforme a ese razonamiento podría afirmarse que, al estar ambas ramas del Derecho informadas por los principios del Derecho Público Punitivo del Estado, a falta de precisos principios del Derecho Administrativo Sancionador, a este debieran aplicársele los principios de aquel y no los del Derecho Penal, como concluyen tales autores, o bien, los de este último, pero, claro está, por "regla general", es decir, con excepciones y/o con matices, según corresponda ${ }^{25}$.

Reiteradamente, he sostenido que el Derecho Administrativo Sancionador es una rama autónoma del Derecho, que tiene su "anclaje" en el Derecho Público, en específico en el Derecho Administrativo, con lo cual he querido poner de relieve la finalidad prioritaria que singulariza a esta rama del Derecho, cual es, la protección del interés público, sin perjuicio de otras secundarias como, por ejemplo, dotar de garantías al perseguido ${ }^{26,27}$.

\footnotetext{
${ }^{24}$ En este sentido, Nieto ha planteado que "decir que dos fenómenos son iguales en la realidad no significa necesariamente que hayan de tener el mismo régimen jurídico; de la misma forma que el legislador puede dotar del mismo régimen jurídico figuras que en el mundo real son, sin duda alguna, ontológicamente diferentes”. NiETO, Alejandro, op. cit, (n. 17), p. 128. Y en el mismo sentido Peman Gavín ha observado que gran parte de la doctrina "ha otorgado a cuestiones como la propia identidad sustantiva entre el delito y la infracción administrativa un carácter secundario dentro de los problemas del Derecho Sancionador, pues (...) lo esencial es determinar el concreto régimen jurídico aplicable al Derecho Sancionador". Peman Gavín, Ignacio. El Sistema Sancionador Español. Hacia una Teoría General de las Infracciones y Sanciones Administrativas. - $1^{\text {a }}$ ed.- Barcelona: Editorial Cedecs, 2000, p. 27.

25 Respecto del argumento relativo al ius puniendi sostiene Nieto: "El enorme éxito de tal postura -elevada ya a la categoría de dogma incuestionable- se debe en parte a razones ideológicas, a que así se atempera el rechazo que suelen producir las actuaciones sancionadoras de la Administración, de corte autoritario, y, en parte, a razones técnicas, en cuanto que gracias a este entronque con el Derecho Público estatal se proporciona al Derecho Administrativo Sancionador un soporte conceptual y operativo del que antes carecía". Y en mismo sentido que nosotros, Nieto ha planteado: "Porque una vez integrada la potestad sancionadora de la Administración en el ius puniendi del Estado, lo lógico sería que aquella se nutriera de la sustancia de la potestad matriz, y, sin embargo, no sucede así, sino que la potestad administrativa a quienes realmente se quiere subordinar es a la actividad de los Tribunales penales y de donde se quiere nutrir al Derecho Administrativo Sancionador es del Derecho Penal, y no del Derecho público estatal”. NieTo, Alejandro, op. cit. (n. 17), p. 22.

${ }^{26}$ En este sentido, Nieto ha planteado: "Aquí hay, por tanto, una sustitución ilegítima que importa denunciar, y en su caso corregir, para terminar asumiendo todas las consecuencias del dogma. Imagínese, en efecto, lo que sucedería si fuera el Derecho público estatal, y no el Derecho Penal, el que inspirara al Derecho Administrativo Sancionador. El Derecho Penal, desde la perspectiva en que aquí se le contempla, es un Derecho garantista, exclusivamente preocupado por el respeto a los derechos del inculpado; mientras que en el Derecho público estatal, sin menosprecio de las garantías individuales, pasa a primer plano la protección y fomento de los intereses generales y colectivos. En otras palabras, si de veras se creyera en el dogma básico - del que verbalmente tanto se alardea-, habría que rectificar los planteamientos al uso y trasladar el Derecho Administrativo Sancionador desde los campos del Derecho Penal -donde ahora se encuentra o, al menos, quiere instalársele- a los del Derecho Público estatal. Con lo cual terminaría recuperando la potestad sancionadora de la Administración la fibra administrativa que ahora se le está negando. En definitiva, contra viento y marea hay que afirmar que el Derecho Administrativo Sancionador es, como su mismo nombre indica, Derecho Administrativo engarzado directamente en el Derecho Público estatal y no un Derecho Penal vergonzante; de la misma manera que la potestad administrativa sancionadora es una potestad ajena a toda potestad atribuida a la Administración para la gestión de los intereses públicos. No es un azar, desde luego, que hasta el nombre del viejo Derecho Penal Administrativo haya sido sustituido desde hace años por el más propio de Derecho Administrativo Sancionador”. NiETO, Alejandro, op. cit. (n. 17), pp. 26-27. Por su parte De Palma del Teso ha sostenido: "que mientras el Derecho Penal es un ámbito exclusivamente punitivo, cuya única referencia es el Derecho Público Estatal, el Derecho Sancionador Administrativo no solo debe mirar hacia el Ordenamiendo Público Estatal, sino también hacia el propio Derecho Administrativo en el que está inserto; razón por la cual los mismos principios no tienen un contenido homogéneo en uno y otro ámbito. (...) Razones todas las vistas que justifican y exigen el recurso al Derecho Penal, por tener en él su asiento los principios aplicables a todo el Ordenamiento Punitivo, y ser referencia obligada en el proceso de elaboración de una dogmática propia del Derecho
} 
Tesis que pareciera suscribir nuestro Tribunal Constitucional si se advierte que aquel, al referirse sobre esta cuestión, siempre ha empleado la expresión "Derecho Administrativo Sancionador" y no "Derecho Penal Administrativo" 28.

\section{LOS PRINCIPIOS DEL DERECHO ADMINISTRATIVO SANCIONADOR}

Los principios que informan al Derecho Administrativo Sancionador son de dos clases: los sustantivos y los adjetivos (o procedimentales).

\section{LOS PRINCIPIOS SUSTANTIVOS DEL DERECHO ADMINISTRATIVO SANCIONADOR}

Sin perjuicio de lo aseverado con anterioridad, en relación a la autonomía del Derecho Administrativo Sancionador respecto del Derecho Penal, hay un hecho inobjetable: el primero, no obstante ser cada vez más extendido y lesivo, aún no tiene la solidez dogmática que se aprecia en el segundo. Frente a este estado de cosas preciso es determinar qué principios han de informar a esta incipiente rama del Derecho. En mi opinión, corresponde aplicar, como medida de urgencia y hasta que los principios del Derecho Administrativo Sancionador adquieran claros y precisos contornos -lo que no acontece actualmente-, como pauta y cota máxima, los principios que informan al Derecho Penal. Como pauta pues ellos, en su conjunto, establecen los lineamientos generales que deberían considerarse para tal propósito, sin que ello importe necesariamente aplicar cada uno de dichos principios y con el mismo alcance que en el Derecho Penal (en otras palabras, admito la "importación", pero en caso alguno el "contrabando" de ellos) y como cota máxima, pues en la traslación de tales principios al Derecho Administrativo Sancionador, no es posible ser "más penalista que los penalistas", esto es, el alcance que en él han de tener, deberá ser siempre más flexible que en el Derecho Penal, conclusión que resulta, a todas luces, evidente si se considera que en dicha sede en caso alguno podría afectarse la libertad personal del perseguido ${ }^{29}$.

Sancionador Administrativo, teniendo en cuenta, claro está, la diferencias existentes entre los dos ámbitos y que entre ellos no existe relación de jerarquía”. De PALMA Del TeSO, Ángeles. op. cit. (n. 17), pp. 39-40.

27 Plantea Nieto en este sentido que "Las garantías del inculpado son ciertamente irrenunciables; pero ya no es tan cierto que tengan que proceder del Derecho Penal, puesto que el Derecho público estatal y el Derecho Administrativo están perfectamente capacitados para crear un sistema idóneo propio. Otra cosa es que hasta ahora no lo hayan hecho y que, en consecuencia, para remediar esta ausencia, haya habido, de forma provisional y urgente, que tomar a préstamo las técnicas garantistas del Derecho Penal, pero a conciencia de que no son siempre adecuadas al Derecho Administrativo Sancionador". Nieto, Alejandro, op. cit. (n. 17), pp. 22 y 23.

${ }^{28}$ Véanse al respecto las STC Nos 479 y 480.

29 En el mismo sentido, Nieto ha planteado que "el Derecho Administrativo Sancionador no debe ser construido con los materias y con las técnicas del Derecho Penal sino desde el propio Derecho Administrativo, del que obviamente forma parte, y desde la matriz constitucional y del Derecho Público estatal. Conste, sin embargo, que esta confesada inspiración no es consecuencia de un prejuicio ideológico, no mucho menos profesoral, sino resultado de haber constatado el fracaso de una metología -la extensión de los principios del derecho Penal- que ha demostrado no ser certera desde el momento en que la traspolación automática es imposible y que las matizaciones de adaptación son tan difíciles como inseguras; hasta tal punto que el resultado final nada tiene que ver con los principios originarios, cuyo contenido tiene que ser profundamente falseado. Para rectificar este fracaso no hay más remedio que volver a empezar desde el principio y en el 
En armonía con lo señalado anteriormente, el Tribunal Constitucional, a través de su sentencia $N^{\circ} 244$, de $1996^{30}$, sostuvo que tanto el Derecho Penal como el Derecho Administrativo Sancionador son manifestaciones del ius puniendi del Estado, de lo cual infieren que los principios del primero son aplicables al segundo, aunque "por regla general", esto es, conforme puede fácilmente inferirse, de forma matizada, aunque también permitiría desviaciones del esquema penal. Con ello, el Tribunal Constitucional, tácitamente reconoció la autonomía del "Derecho Administrativo Sancionador", prueba de lo cual es el empleo, hasta el día de hoy, de dicha expresión, para referirse a esta materia.

Sin perjuicio de lo anterior, recientemente a través de los fallos Nos 479 y 480 , de $2006^{31}$, dicha Magistratura señaló que a pesar de existir algunas diferencias entre pena y sanción, ambas son manifestación del ius puniendi del Estado, de lo cual infiere que el estatuto constitucional establecido en el $\mathrm{N}^{\circ} 3$ del artículo 19 de la Constitución, es aplicable "con matices" al Derecho Administrativo Sancionador. Lo anterior constituye, a mi juicio, un importante cambio jurisprudencial, pues la voz "con matices", que emplean estas sentencias, es más restrictiva que la utilizada por la $\mathrm{N}^{\circ} 244$ - "por regla general"-, ya que, a diferencia de esta última, no autorizarían desviaciones o excepciones al modelo penal, con lo cual, erróneamente, a mi juicio, el Tribunal Constitucional ha acercado el Derecho Administrativo Sancionador al Derecho Penal, poniendo con ello en entredicho su autonomía -que le es consustancial, conforme he explicado-, y ha enfatizado, a su vez, su rol garantista, en desmedro de aquel que lo singulariza: la protección del interés público.

En este contexto, por tanto, posible es concluir, tal como lo estableció el Mensaje del Proyecto de Bases de Procedimientos Administrativos Sancionatorios ${ }^{32}$-luego retirado-, que "con las adecuaciones de rigor" son "principios sustantivos del derecho administrativo sancionador los de legalidad, irretroactividad, tipicidad, responsabilidad personal, prohibición de la privación de libertad, proporcionalidad y prescriptibilidad"33.

\section{LOS PRINCIPIOS ADJETIVOS DEL PROCEDIMIENTO ADMINISTRATIVO SANCIONADOR}

La Administración, en el ejercicio de sus potestades sancionadoras, debe siempre y en todo caso conformarse a un procedimiento idóneo que satisfaga debidamente los impe-

\footnotetext{
principio están, como he repetido, la Constitución, el Derecho Público estatal y el Derecho Administrativo, por este orden. En esta tarea la presencia del Derecho Penal es no ya solo útil sino imprescindible. El Derecho Penal ha de seguir operando, no obstante y en todo caso, como punto de referencia, como pauta técnica y, sobre todo, como cota de máxima de las garantías individuales que el Derecho Administrativo Sancionador debe tener siempre presentes". NiETO, Alejandro, op. cit. (n. 17), p. 28.

${ }^{30}$ En efecto, esta sentencia en lo medular sostuvo: "Que, los principios inspiradores del orden penal contemplados en la Constitución Política de la República han de aplicarse, por regla general, al derecho administrativo sancionador, puesto que ambos son manifestaciones del ius puniendi propio del Estado" (C-9º).

${ }^{31}$ En lo medular estos fallos señalaron: "Que el principio de legalidad es igualmente aplicable a la actividad sancionadora de la administración en virtud de lo prescrito en los dos últimos incisos del numeral 3 del artículo 19 de la Carta Fundamental. Aun cuando las sanciones administrativas y las penas difieren en algunos aspectos, ambas pertenecen a una misma actividad sancionadora del Estado -el llamado ius puniendi- y están, con matices, sujetas al estatuto constitucional establecido en el numeral $3^{\circ}$ del artículo 19". (C-5).

32 Boletín No 3475-06.

33 Mensaje de S.E. el Presidente de la República con el que se inicia un proyecto de ley que establece las bases de los procedimientos administrativos sancionatorios (Mensaje 541-350), p. 14.
} 
rativos del justo y racional procedimiento, en los términos señalados en el artículo 19 No 3 de la Constitución ${ }^{34}$. Por tanto, informan al Derecho Administrativo Sancionador no solo principios sustantivos, sino que también de orden adjetivo o procedimentales, que si bien es cierto han de guardar cierta simetría con aquellos que informan al proceso penal, no lo es menos que, atendidas las sustantivas diferencias entre la persecución penal y sancionadora-administrativa-, necesario es considerar desde ya matices, sino excepciones, como se ha explicado precedentemente.

Estos principios de orden procedimental que informan al Derecho Administrativo Sancionador pueden desglosarse, sintéticamente, de la siguiente manera:

a) Derecho al procedimiento administrativo sancionador. La imposición de una sanción administrativa debe siempre ser el resultado de un procedimiento idóneo seguido por un organismo administrativo. No resulta constitucionalmente admisible, en consecuencia, aun cuando una norma legal así lo permita expresamente -la que de existir no dudaría en tachar de inconstitucional-, la imposición de tales sanciones "de plano" 35.

b) Reserva de ley del procedimiento administrativo sancionador. No basta la existencia de un procedimiento sancionador administrativo, necesario es que aquel esté consultado en una norma de rango legal. En todo caso, esto no quiere decir de antemano que se impida la colaboración de normas infralegales para tal cometido (v.gr., reglamento y auto acordados), ya que aquello posible es, a mi juicio, siempre que la ley haya reglado los aspectos sustantivos del procedimiento administrativo sancionador y tales normas lo precisen sin restringir los derechos y garantías del perseguido ${ }^{36}$.

c) El procedimiento sancionador administrativo debe satisfacer las exigencias de un justo y racional procedimiento. El procedimiento administrativo sancionador debe satisfacer la garantía de un justo y racional procedimiento, lo que exige que aquel consulte una serie de derechos y garantías para el perseguido en dicha sede, insertos en el concepto de debido

\footnotetext{
${ }^{34}$ En idéntico sentido Aguerrea Mella ha sostenido: "Asimismo, con ello se ratifica lo sostenido por la mejor doctrina nacional en cuanto a que en los procedimientos administrativos, cualesquiera que sean, es enteramente aplicable el art. 19 No 3 de la Constitución y que las decisiones que emitan los órganos de la Administración deben basarse en un proceso previo legalmente tramitado, correspondiéndole al legislador contemplar los elementos que lo hagan racional y justo". Aguerrea Mella, Pedro. "Límites procesales a las potestades sancionadoras de la Administración en la jurisprudencia del Tribunal Constitucional”, en: Sanciones Administrativas y Derechos Fundamentales, Regulación y Nuevo intervencionismo - $1^{\mathrm{a}}$ ed.-, Santiago: Conferencias Santo Tomás de Aquino, 2005, p. 96.

35 En este sentido, el Tribunal Constitucional ha resuelto: "Que, en consecuencia, aun cuando se trate de un "resolver de plano" con las características antes indicadas, esta Magistratura concluye que resultaría contrario a un procedimiento racional y justo que la Corte de Apelaciones proceda de este modo, sin relación pública ni escuchar ella misma a la parte afectada al decidir los cargos que se formulan en contra de la requirente, pues lo que debe decidir en la gestión pendiente es una cuestión trascendente, no solo para derechos esenciales de la requirente, sino también y especialmente delicada para la independencia de la que debe gozar un secretario cuando, obrando como juez subrogante, dicta una sentencia definitiva”. (STC Rol No 747, C-11).

36 En este sentido el Tribunal Constitucional ya ha observado que habiéndose constatado la "omisión de toda norma regulatoria del proceso y procedimiento a través del cual pueden ser impuestas aquellas sanciones, contemplando la defensa de rigor, entre otras situaciones constitucionalmente anómalas", no es posible sino concluir que "las omisiones normativas que evidencia ese precepto en formación impiden que pueda considerarse cumplido el cúmulo de exigencias previstas en el artículo 19 No 3 de la Constitución. Consiguientemente, el Tribunal debe declarar que tal disposición del proyecto infringe el fondo del precepto constitucional señalado, reproche de inconstitucionalidad material que así será decidido en la parte resolutiva de esta sentencia". (STC Rol No 437, C-22 y 23)
} 
proceso, en especial los de defensa jurídica ${ }^{37}$, de presunción de inocencia ${ }^{38}$ y de acceso a la justicia ${ }^{39}$.

\section{EL CONCEPTO DE SANCIÓN ADMINISTRATIVA}

Teniendo en consideración, como se ha señalado precedentemente, que la potestad sancionadora de la Administración debe necesariamente conformarse a una serie de principios, tanto sustantivos como adjetivos, lo óptimo sería establecer, con cierto grado de certeza, un criterio conforme al cual distinguir qué actuación lesiva de derechos que ejecute la Administración (entre los cuales se cuentan, v.gr., la revocación de un acto favorable, la expropiación, la imposición de medidas de coacción directa, la adopción de medidas cautelares, la imposición de multas, etcétera), pueden ser considerados, para estos efectos, una "sanción administrativa" 40.

\footnotetext{
${ }^{37}$ En este sentido el Tribunal Constitucional ha aseverado: "Que, de lo razonado en los considerandos precedentes, fluye que los principios del artículo 19 No 3 de la Constitución, en la amplitud y generalidad ya realzada, se aplican, en lo concerniente al fondo o sustancia de toda diligencia, trámite o procedimiento, cualquiera sea el órgano estatal involucrado, trátese de actuaciones judiciales, actos jurisdiccionales o decisiones administrativas en que sea, o pueda ser, afectado el principio de legalidad contemplado en la Constitución, o los derechos asegurados en el artículo 19 No 3 de ella, comenzando con la igual protección de la ley en el ejercicio de los atributos fundamentales. Además y de los mismos razonamientos se sigue que los principios contenidos en aquella disposición constitucional rigen lo relativo al proceso racional y justo, cualquiera sea la naturaleza, el órgano o el procedimiento de que se trate, incluyendo los de índole administrativa, especialmente cuando se ejerce la potestad sancionadora o infraccional. Por consiguiente, el legislador ha sido convocado por el Poder Constituyente a ejercer su función en plenitud, esto es, tanto en cuestiones sustantivas como procesales, debiendo en ambos aspectos respetar siempre lo asegurado por la Carta Fundamental en el numeral referido"; (STC Rol No 437, C-17\%). En tal dirección se han pronunciado las sentencias Rol Nos 389 C-13 y 376 C-35º.

38 El Tribunal Constitucional ha establecido -en relación a la responsabilidad penal, pero aplicable igualmente, "por lo general", a la responsabilidad administrativa-: "la prohibición de presumir de derecho la responsabilidad penal constituye un principio que es concreción de la dignidad de la persona humana, consagrada como valor supremo en el artículo $1^{\circ}$ de la Constitución Política, y del derecho a la defensa en el marco de un debido proceso, en los términos que reconoce y ampara el artículo 19 No 3 de la Ley Fundamental”, como esta Magistratura sentenció en fallo recaído sobre la causa Rol No 519-2006. Acercándonos a la especie, la prohibición señalada representa un soporte sustancial a gran parte de las garantías de la doctrinariamente bien llamada igualdad ante la justicia que en nuestro ordenamiento adoptó la peculiar denominación "igual protección de la ley en el ejercicio de sus derechos”, dando sustento a la presunción de inocencia en materia penal, de unánime reconocimiento doctrinario, legislativo y jurisprudencial”; (STC Rol No 825 C-24o).

39 En este sentido el Tribunal Constitucional ha establecido: "No se repetirán aquí los razonamientos que, en las sentencias referidas, han fundado tal conclusión, la que además parece evidente: el derecho de acceso a la justicia forma parte de la igual protección de la ley en el ejercicio de los derechos y del derecho al debido proceso, consagrado por la Constitución”. (STC Rol No 1279 C-14º).

${ }^{40}$ El Mensaje del proyecto de ley de bases de los procedimientos administrativos sancionatorios, señaló: "A primera vista parece del todo evidente qué es una sanción administrativa, mas como se verá a continuación son muchos los casos que parecen serlo pero que en definitiva no lo son. Cuestión que no es un mero divagar en cuestiones semánticas, pues solo a aquello que es sanción administrativa le son aplicables los principios del derecho administrativos sancionador, sean sustanciales o procedimentales. Así, por ejemplo, la expropiación para la construcción de una carretera si es considerada sanción arrastraría consigo los principios del derecho Administrativos sancionador, es decir los principios penales con matices". Asimismo se ha afirmado: "Estas garantías (las que deben respetarse al imponerse una sanción administrativa nota nuestra-) suponen para los ciudadanos mayores derecho que los que tienen cuando se relacionan con la Administración en el seno de otra potestad (de policía por ejemplo), e implican por tanto correlativas cargas para la Administración en tanto que para no quebrantar aquellos debe ser "más cuidadosa" que lo habitual. Es decir, así como para sancionar necesita la Administración que haya una norma con rango de ley que describa con carácter previo y suficiente detalle la infracción (principio de legalidad), que haya al menos negligencia en la actuación del sujeto (culpabilidad), que no haya
} 
Llamativamente, a no ser por contadas excepciones, nuestra doctrina no ha abordado este tópico ${ }^{41}$. De ello posible es inferir que la discusión que ha habido en torno al Derecho Administrativo Sancionador, en específico sobre los principios que lo informan, ha partido del supuesto -no reconocido expresamente, por cierto- de que cualquier actuación lesiva desplegada por la Administración importa una "sanción administrativa", produciendo con ello no solo una hiperinflación del concepto sino que, además, una ampliación desmedida de la órbita de acción de los principios del Derecho Administrativo Sancionador, que preciso es corregir ${ }^{42}$.

Sabido es que sanción es la "consecuencia jurídica desfavorable que el incumplimiento de un deber produce respecto del obligado" 43 , o bien, la "pena que la ley establece para el que la infringe" 44 , en otras palabras, la garantía de cumplimiento de una norma jurídica; mas en cuanto al concepto de "sanción administrativa" no existe el mismo grado de coincidencia. Así, a modo ejemplar, se ha señalado que esta última es "un mal jurídico que la Administración infringe a un administrado responsable de una conducta antecedente. Son penas en sentido técnico impuestas por la Administración, utilizando sus prerrogativas (...)"45, o bien, que es "cualquier mal infringido por la Administración a un administrado como consecuencia de una conducta ilegal a resultas de un procedimiento administrativo y con una finalidad puramente represora" 46 , por mencionar algunas definiciones sugeridas por la doctrina.

Sin perjuicio de tales definiciones, a mi juicio, la sanción administrativa es un concepto jurídico indeterminado, como muchos otros que pueden apreciarse en el Derecho Público (v.gr., la falta de servicio), y precisamente por ello vano es todo intento por definirla y, a su vez, peligroso, pues con ello se corre el riesgo de rigidizar en demasía su concepto, incluyendo en ella hipótesis dudosas, o bien, excluyendo otras que al parecer sí tendrían tal carácter ${ }^{47}$. Corresponde a la jurisprudencia, en consecuencia, determinar su

pasado el tiempo que da lugar a la prescripción, que el castigo sea adecuado a las circunstancias concurrentes (proporcionalidad), que no se impongan dos castigos por un solo hecho (non bis in idem), o seguir un procedimiento donde se acrediten suficientemente los hechos partiendo de la inocencia del ciudadano, nada de lo anterior será preciso, o al menos no de un modo tanto riguroso, cuando se trate de realizar otras actuaciones que aun incidiendo en la esfera jurídica de los administrados no tengan la consideración de sanciones". (AbogaCía General Del Estado, Dirección DEL SERVICiO Jurídico Del Estado. Manual de Derecho Administrativo Sancionador. -1a ed.- Madrid: Editorial Thomson-Civitas, 2005, p. 111.

41 Bermúdez Soto, Jorge. "Elementos para definir las sanciones administrativas", en Revista Chilena del Derecho, Facultad de Derecho, Pontificia Universidad Católica de Chile, Número Especial, 1998, pp. 323 y ss.

42 Huergo Lora, Alejandro. Las Sanciones Administrativas. -1 $1^{\text {a }}$ ed.- Madrid: Editorial Iustel, 2007, pp. 187 y ss. Pemán GAVÍN, Ignacio, op. cit. (n. 24), pp. 33 y ss.

43 Couture, Eduardo J. Vocabulario Jurídico. - $1^{\text {a }}$ ed.- Montevideo: Biblioteca de Publicaciones Oficiales de la Facultad de Derecho de la Universidad de la República, 1960, p. 544.

${ }_{44}$ Diccionario de la Real Academia de la Lengua Española. -21 a ed.- Madrid: Espasa Calpe, 1992, p. 1304.

45 Carretero Pérez, Adolfo y Carretero Sánchez, Adolfo. op. cit. (n. 17), p. 172.

46 SuAY Rincón, José. Sanciones Administrativas. -1 a ed- Bolonia: Publicaciones del Real Colegio de España, 1989, p. 55.

47 En este sentido, Huergo Lora ha señalado: "El sometimiento de las sanciones administrativas a principios y garantías penales, es decir, a un régimen jurídico específico diferente del que se aplica a otros actos de gravamen, exige identificarlas con precisión. Esa tarea no puede corresponderle al legislador, pues ello le permitiría eludir a voluntad la aplicación de las garantías establecidas por la Constitución para las sanciones. No es raro, por otro lado, que los particulares intenten extender el concepto de sanción, pidiendo a los Tribunales que reconozcan esa naturaleza a medidas que no la tienen. En el fondo late una paradoja: si ese régimen especial de las sanciones consisten en último términos en un plus de garantías que tiene como finalidad proteger a los particulares frente a medidas de efectos especialmente graves para su esfera jurídica, no se entiende que las multas, como la resolución de un contrato o la revocación de una autorización”. HUERGO LORA, Alejandro. op. cit. (n. 42), p. 186. 
ocurrencia en cada caso concreto y a la doctrina, a lo más, fijar sus lineamientos generales. Bajo este entendido, a continuación expondré cuatro elementos que, a mi juicio, configuran el núcleo esencial de toda "sanción administrativa":

a) La sanción administrativa debe ser impuesta por un órgano administrativo. Ciertamente la sanción administrativa debe ser impuesta por un organismo administrativo que tenga atribuida por ley facultad expresa en ese sentido. En consecuencia, no podría ser tal, por ejemplo, la medida lesiva de derechos impuesta por un organismo que no revista tal carácter, o bien, por un organismo administrativo que se ampare para ello en una norma reglamentaria, o bien, en una norma legal que solo le confiera otras potestades, v.gr., de inspección y no expresamente la de sancionar, por muy ligadas que a esta estén ${ }^{48}$.

b) La sanción administrativa debe importar una lesión o menoscabo de derechos o la imposición de un deber para un particular. La sanción administrativa debe importar para el afectado un menoscabo o lesión en sus derechos o la imposición de un deber -el cual necesariamente debe estar establecido en una disposición legal-. Si la medida impuesta por un organismo administrativo carece de esta cualidad, en caso alguno podrá ser considerada "sanción administrativa".

c) La sanción administrativa debe haber sido establecida por el ordenamiento jurídico como reacción a la contravención de este. Toda sanción administrativa debe ser, necesariamente, la reacción frente a una acción: la realización, por acción u omisión, de una infracción administrativa, tipificada como tal por ley.

d) La sanción administrativa debe ser impuesta con un solo fin: la represión o castigo de un ilícito administrativo. La sanción debe ser establecida con un solo fin: reprimir o castigar la realización de un ilícito administrativo. Si se impusiera una "sanción administrativa” con otros fines, nos hallaríamos frente a una hipótesis de desviación de poder ${ }^{49}$, que la tornaría arbitraria y que, a su vez, impediría calificarla como tal.

\section{CONCLUSIONES}

1. El Derecho Administrativo Sancionador se halla en relación de autonomía respecto del Derecho Penal, está "anclado" en el Derecho Público y en específico en el Derecho Administrativo y, por ello, sirve un rol prioritario, cual es, resguardar el interés público.

2. No obstante su autonomía, ante la inexistencia de un cuerpo dogmático sólido en cuanto a sus principios, por razones de urgencia, deben serle aplicados, como pauta y cota máxima, aquellos que informan al Derecho Penal, pero, claro está, que con

\footnotetext{
48 Sото Kloss, Eduardo. "Es tan “delgada” la línea que separa "fiscalizar” de “juzgar”, en Gaceta Jurídica, No 331, 2007, pp. 35 y ss.

49 Sobre el particular, entre otras, véase: SILVA TAMAYO, Gustavo, Desviación de poder y abuso de derecho. - $1^{\mathrm{a}}$ ed.- Buenos Aires: Editorial LexisNexis, 2006. SÁNCHEZ ISAC, Jaime. La desviación de poder en los derechos francés, italiano y español. -1a ed.- Madrid: Instituto de Estudios de Administración Local, 1973. ChinChilla MARín, Carmen. La desviación de poder-2a ed.- Madrid: Editorial Civitas, 1999. CASTILlO BlanCO, Federico. La interpretación y aplicación del ordenamiento jurídico público - $1^{\text {a }}$ ed.- Madrid: Instituto Nacional de Administración Pública, 2007.
} 
excepciones o matizaciones, según corresponda. Por otra parte, en el plano adjetivo o procedimental, la Administración, en el ejercicio de estas potestades, igualmente, deberá observar todos aquellos principios que deriven de la garantía del justo y racional procedimiento.

3. La sanción administrativa es un concepto jurídico indeterminado que el juez deberá precisar en cada caso concreto. Sin perjuicio de ello, posible es establecer algunas características que configuran lo que he denominado su núcleo esencial: a) debe ser impuesta por un organismo administrativo, b) debe importar para el infractor una lesión, o bien, la imposición de un deber, c) debe ser consecuencia inequívoca de la comisión de una infracción administrativa, y d) debe ser impuesta con un solo fin: la represión o el castigo.

\section{REFERENCIAS BIBLIOGRÁFICAS}

ABOGACÍA GENERAL DEL ESTADO Y DIRECCIÓN DEL SERVICIO JURÍDICO DEL ESTADO. Manual de Derecho Administrativo Sancionador. $1^{\text {a }}$ edición, Madrid, Editorial Thomson-Civitas, 2005 .

Aguerrea Mella, Pedro. "El estatuto constitucional de la penas. Su aplicación a las sanciones administrativas conforme a los antecedentes de la Comisión de Estudio de la Nueva Constitución”. En: Sanciones Administrativas y Derechos Fundamentales, Regulación y Nuevo Intervencionismo. $1^{\text {a }}$ edición, Santiago, Conferencias Santo Tomás de Aquino, 2005.

"Límites procesales a las potestades sancionadoras de la Administración en la jurisprudencia del Tribunal Constitucional". En: Sanciones Administrativas y Derechos Fundamentales, Regulación y Nuevo intervencionismo. $1^{\text {a }}$ edición, Santiago, Conferencias Santo Tomás de Aquino, 2005.

Alarcón Sotomayor, Lucía. El Procedimiento Administrativo Sancionador y los Derechos Fundamentales. $1^{a}$ edición, Madrid, Thomson-Civitas, 2007.

AlCALDE Rodríguez, Enrique. "La personalidad jurídica y el poder sancionador de la Administración”, en Revista Actualidad Jurídica, Universidad del Desarrollo, N 1, enero 2000, pp. 183 y ss.

"Bienes Jurídicos protegidos y potestad sancionadora de la Administración". En: Sanciones Administrativas y Derechos Fundamentales, Regulación y Nuevo intervencionismo. $1^{a}$ edición, Santiago, Conferencias Santo Tomás de Aquino, 2005.

Alonso Madrigal, Francisco Javier. Legalidad de la Infracción Tributaria (Reserva de ley y tipicidad en el Derecho Tributario Sancionador). $1^{\text {a }}$ edición, Madrid, Dykinson, 1998.

ARANCIBIA MATTAR, Jaime. "Control judicial de sanciones administrativas en materia económica. Notas para un análisis crítico del caso británico". En: Sanciones Administrativas y Derechos Fundamentales, Regulación y Nuevo intervencionismo. 1a edición, Santiago, Conferencias Santo Tomás de Aquino, 2005.

Aróstica Maldonado, Iván. "Algunos Problemas del Derecho Administrativo Penal", en Revista de Derecho, Universidad de Concepción, $\mathrm{N}^{\circ} 182,1987$, pp. 71 y ss.

"El Derecho Administrativo Sancionador y la Proporcionalidad de los Actos Administrativos", en Revista de Derecho y Jurisprudencia, Tomo LXXXIV, 1987, pp. 109 y ss.

"Un Lustro de Sanciones Administrativas (1988-1992)", en Revista de Derecho Público, Facultad de Derecho de la Universidad de Chile, No 50, pp. 173 y ss.

"Sanciones administrativas y prescripción". En: Sanciones Administrativas y Derechos Fundamentales, Regulación y Nuevo intervencionismo, $1^{a}$ edición, Santiago Conferencias Santo Tomás de Aquino, 2005. 
Avilés HernÁndeZ, Víctor Manuel. "Algunas Consideraciones Constitucionales relativas al Orden Público Económico y el Derecho Penal”, en Revista de Derecho Público, No 62, 2000, pp. 169 y ss.

Bajo, Miguel, y Bacigalupo, Silvina. Derecho Penal Económico, Madrid, Editorial Centro de Estudios Ramón Areces, 2001.

Bermúdez Soto, Jorge. "Elementos para definir las sanciones administrativas", en Revista Chilena del Derecho, Número Especial, 1998, pp. 323 y ss.

Calvo Charro, María. Sanciones Medioambientales. 1a edición, Madrid, Editorial Marcial Pons, 1999.

Carnevali Rodríguez, Raúl. Derecho penal y derecho sancionador en la Unión Europea. Granada, Editorial Comares, 2001.

Cobo Olvera, Tomás. El procedimiento administrativo sancionador tipo. Barcelona, Editorial Bosch, 2001.

De Palma Del Teso, Ángeles. El principio de culpabilidad en el Derecho Administrativo Sancionador. Madrid, Editorial Tecnos, 1996.

Dellis, George. Droit Pénal et Droit Administratif. La influence des principes du droit penal sur le droit administratif répressif. París, Libraire Générale de Droit et de Jurisprudence, 1997.

Evans EspiñeIra, Eugenio. Derecho Eléctrico. 1a edición, Santiago, Editorial LexisNexis, 2003.

EVANS EspiñeIRA, Eugenio. "Los tipos penales administrativos en la Ley 18.410, orgánica de la Superintendencia de Electricidad y Combustibles", en Revista de Derecho Administrativo Económico de Recursos Naturales, Vol III/N² ${ }^{\circ}$, octubre-diciembre 2001, pp. 637 y ss.

Garberí Llobregat, José y Buitrón Ramírez, Guadalupe. El Procedimiento Administrativo Sancionador. Valencia, Editorial Tirant lo Blanch, 2001.

GARCÍA DE ENTERRÍA, Eduardo. “El problema jurídico de las sanciones administrativas”, en Revista Española de Derecho Administrativo, $\mathrm{N}^{\circ} 10,1976$, p. 409 y ss.

Huergo Lora, Alejandro. Las Sanciones Administrativas. 1ª edición, Madrid, Editorial Iustel, 2007.

Lesmes Serrano, Carlos y otros. Derecho Penal Administrativo (Ordenación del Territorio, Patrimonio histórico y Medio Ambiente). Granada, Editorial Comares, 1997.

Retortillo, Martín, “Multas administrativas", en Revista Administración Pública, N 71.

Maljar, Daniel E.. El Derecho Administrativo Sancionador. $1^{\text {a }}$ edición, Buenos Aires, Editorial Ad-Hoc, 2004

Mendoza ZÚNiga, Ramiro y Oddo BeAs, Blanca. "Del recurso de reposición administrativo y su aplicación ante la ley especial (el caso de la legislación de telecomunicaciones)”, en Revista Actualidad Jurídica $\mathrm{N}^{\circ}$ 8, julio 2003, p. 286.

MENDOZA ZúÑIGA, Ramiro. "Acerca del principio general de intransmisibilidad de las multas y en particular cuando ellas no se encuentran ejecutoriadas". En: Sanciones Administrativas y Derechos Fundamentales, Regulación y Nuevo intervencionismo, $1^{\text {a }}$ edición, Santiago, Conferencias Santo Tomás de Aquino, 2005.

MeSEguer Yebra, Joaquín. El principio “non bis in idem” en el procedimiento administrativo sancionador. $1^{\mathrm{a}}$ edición, Barcelona, Editorial Bosch, 2000.

Meseguer Yebra, Joaquín. La Tipicidad de las Infracciones en el Procedimiento Administrativo Sancionador, $1^{\text {a }}$ edición, Barcelona, Editorial Bosch, 2001.

Navarro Beltrán, Enrique. "Notas sobre Potestad Sancionatoria de la Autoridad Administrativa y Principio de Legalidad", en Revista de Derecho Público, N 67, pp. 118 y ss.

Nieto García, Alejandro. Derecho Administrativo Sancionador. $3^{\text {a }}$ edición, Madrid, Editorial Tecnos, 2002.

Orena DomíngueZ, Aitor. Infracciones y Sanciones Tributarias: un Estudio Jurisprudencial. Bilbao, Servicio Editorial Universidad del País Vasco, 2002. 
Peman Gavín, Ignacio. El Sistema Sancionador Español. Hacia una Teoría General de las Infracciones y Sanciones Administrativas. Barcelona, Editorial Cedecs, 2000.

Quirós Lobos, José María. Principios de Derecho Sancionador. Granada, Editorial Comares, 1996.

RosınI, Emilio. Sanzioni administrative. Milano, Giuffrè Editore, 1991.

RomÁn Cordero, Cristian. "Derecho Administrativo Sancionador: Ser o no ser. He ahí el dilema". En: Pantoja Bauzá, Rolando (coord.). Derecho Administrativo: 120 años de cátedra. $1^{a}$ edición, Santiago, Editorial Jurídica de Chile, 2008, pp. 107 y ss.

Román Cordero, Cristian, "Los principios del Derecho Administrativo Sancionador Chileno", en Revista de Derecho Público, No 69, I, pp. 24 y ss.

"Neoadministrativismo(s)", en Revista de la Asociación Internacional de Derecho Administrativo, No 4, pp. 263 y ss.

Santamaría Pastor, Juan Alfonso. Principios de Derecho Administrativo. $3^{a}$ edición, Madrid, Editorial Centro de Estudios Ramón Areces, Vol II, 2002.

SanZ Gandasegui, Francisco. La potestad sancionatoria de la administración: la Constitución española y el Tribunal Constitucional. Madrid, Edersa, 1985.

Sото KLOSS, Eduardo. "Notas para el estudio de la potestad sancionadora de la Administración", en Boletín de Investigaciones, Facultad de Derecho, Pontificia Universidad Católica de Chile, Nos 44 y 45, 1979/ 1980 , pp. 95 y ss.

SOTO KLOSS, Eduardo. "La impugnación de sanciones administrativas y el derecho fundamental de acceso a la justicia. El "solve et repete" y el Estado de Derecho". En: Sanciones Administrativas y Derechos Fundamentales, Regulación y Nuevo intervencionismo. $1^{\text {a }}$ edición, Santiago, Conferencias Santo Tomás de Aquino, 2005.

SOTO Kloss, Eduardo. "La potestad sancionadora de la Administración, ¿̇se adecua a la Constitución?”. En: Sanciones Administrativas y Derechos Fundamentales, Regulación y Nuevo intervencionismo. $1^{a}$ edición, Santiago, Conferencias Santo Tomás de Aquino, 2005.

Sото Kloss, Eduardo. "Es tan "delgada" la línea que separa "fiscalizar" de "juzgar"”, en Gaceta Jurídica, No 331, 2007, pp. 35 y ss.

Téllez Aguilera, Abel. Seguridad y disciplina penitenciaria. Un estudio jurídico. Madrid, Edisofer, 1998.

Trayter Jiménez, Juan Manuel y Aguado I Cudola, Vicenc. Derecho Administrativo Sancionador: Materiales. Barcelona, Editorial Cedecs, 1995.

Trayter Jiménez, Juan Manuel. Manual de derecho disciplinario de los funcionarios públicos. Madrid, Marcial Pons, 1992.

Vergara Blanco, Alejandro. Derecho Eléctrico. $1^{a}$ edición, Santiago Editorial Jurídica, 2004.

"Esquema de los principios del Derecho Administrativo Sancionador", en Revista de Derecho, Universidad Católica del Norte, Vol .11 N² (2004), p. 142.

ZORNOZA PÉREZ, Juan. El sistema de infracciones y sanciones tributarias (Los principios constitucionales del derecho sancionador). Madrid, Editorial Civitas, 1992. 
